\section{British Thoracic Society Oxygen Guidelines: another clinical brick in the wall}

\author{
B Ronan O'Driscoll
}

The world's first evidence-based guideline for emergency oxygen therapy was published by the British Thoracic Society (BTS) in 2008 and endorsed by 21 other societies and colleges. ${ }^{1}$ The key message in the guideline was very simple: clinicians were advised to avoid hypoxaemia and hyperoxaemia by prescribing a normal or near-normal target oxygen saturation of $94 \%-98 \%$ for most acutely unwell patients and to prescribe a lower range (usually $88 \%-92 \%)$ for patients at risk of hypercapnia, and to use high-concentration oxygen for some conditions such as carbon monoxide poisoning or the immediate management of critical illness. This guidance has informed worldwide clinical practice and research since 2008 and is cited by more than 500 publications. The guideline is now updated and extended with the support of 22 colleges and societies. ${ }^{2}$

Readers will want to know what is new in the 2017 update of the BTS emergency oxygen guideline, published as a supplement to this edition of Thorax. ${ }^{2}$ A concise version of the guideline is available in BMJ Open Respiratory Research. ${ }^{3}$ The evidence review methodology and grading of recommendations follows the National Institute for Health and Care Excellence accredited BTS guideline production process which is based on Scottish Intercollegiate Guidelines Network (SIGN) methodology and adheres to the Appraisal of Guidelines for Research and Evaluation (AGREE) instrument. ${ }^{4}$ The evidence base for the guideline has been updated to August 2013 with bespoke literature searches (and extended to late 2016 for key references). The remit of the guideline is wider now than in 2008. The new guideline covers emergency oxygen use and most other oxygen use in healthcare settings. It also covers short-term oxygen use by healthcare workers outside of healthcare settings. However, domiciliary oxygen use by patients is covered

Respiratory Medicine, Salford Royal Foundation NHS Trust, Salford, UK

Correspondence to Dr B Ronan O'Driscoll, Respiratory Medicine, Salford Royal Foundation NHS Trust, Stott Lane, Salford M6 8HD, UK; ronan.o.driscoll@srft.nhs.uk separately by the BTS guideline for home oxygen use in adults. ${ }^{5}$ The scope of the guideline has been widened to include endoscopy and other procedures requiring sedation, perioperative care including patient-controlled analgesia, palliative care settings including hospices, use of heliumoxygen mixtures (heliox) and nitrous oxide/oxygen mixtures (Entonox), use of CPAP), use of high-flow nasal cannulae, use of oxygen by healthcare professionals in patients' homes and use of oxygen by voluntary rescue organisations and other non-National Health Service first responders.

There have been some landmark publications since 2008 which support the core principles of the guideline. Austin and colleagues reported in 2010 that patients with acute exacerbations of COPD who were randomised to controlled oxygen therapy as per the BTS guideline during prolonged ambulance journeys in Tasmania had low mortality (4\%) compared with patients randomised to high concentration oxygen therapy who had 9\% mortality. ${ }^{6}$ This finding was supported by two observational studies. Roberts et $a l^{7}$ reported mortality of $11 \%$ if $>35 \%$ oxygen was administered to British patients with acute exacerbations of COPD versus $7 \%$ mortality when lower concentrations of oxygen were used, and the need for ventilatory support was 22\% vs $9 \%$. Turner observed an impressively low relative risk of mortality $(0.22)$ when oxygen was used correctly in acute exacerbations of COPD. ${ }^{8}$ Over this time period, researchers in New Zealand have confirmed that the risk of hypercapnia associated with high dose oxygen therapy also extends to patients with obesity-associated hypoventilation, asthma and pneumonia. ${ }^{9-11}$

The 2008 guideline recommended abandonment of the twentieth century practice of giving supplementary oxygen to all patients with suspected myocardial infarction on a 'precautionary basis'. This BTS recommendation was supported strongly by the Air Versus Oxygen in STSegment-Elevation Myocardial Infarction (AVOID) study which reported higher levels of cardiac enzymes among patients with normoxaemia with myocardial infarction with ST segment elevation (STEMI) who were randomised to oxygen therapy compared with those given no supplemental oxygen (unless their saturation fell below 94\%) in Australian ambulances. ${ }^{12} 13$ Patients in that study who were given oxygen therapy had evidence of increased infarct size 3 months later based on cardiac magnetic resonance scans.

The biggest volume of new evidence supporting the 2008 guideline is in the critical care literature. The guideline recommended high concentration oxygen therapy during initial resuscitation and stabilisation of critically ill patients, including those with cardiac arrest, and then aiming for a target range of 94\%$98 \%$ or a patient-specific target saturation range. Several observational studies have found that hyperoxaemia was associated with increased mortality among critical care patients, including survivors of cardiac arrest. Three meta-analyses of these reports have reported the consistency of this finding, but all three reviews commented on the heterogeneity of the available studies and the need for randomised trials. ${ }^{14-16}$ The study of Girardis and colleagues in Italy was published in late 2016. ${ }^{17}$ The authors randomised critical care patients who were likely to require at least 72 hours of mechanical ventilation to either conventional (liberal) oxygen management or to a target range of 94\%-98\%. Mortality was 20\% with liberal oxygen therapy and $12 \%$ with conservative oxygen therapy. Excess deaths in the liberal oxygen group were attributed to shock, liver failure and sepsis. However, the trial was stopped early due to recruitment problems, and the authors advised that further trials will be required to confirm the benefits of conservative oxygen therapy. Four pilot studies have reported no harm, and possible benefits from target saturation range between $88 \%$ and $95 \%$ for critical care patients (permissive hypoxaemia). ${ }^{18-21}$ It will be necessary in future to conduct randomised trials of 'normoxaemia' compared with permissive hypoxaemia in selected subgroups of patients such as those with acute lung injury.

None of the principles or recommendations of the 2008 guideline have been challenged by new evidence, but many of the existing recommendations are supported by new evidence. The Thoracic Society of Australia and New Zealand (TSANZ) has published a regional acute oxygen guideline which is based on the 2008 BTS guideline apart from recommending a target saturation range of $92 \%$ 
$96 \%$ (instead of 94\%-98\%) for patients who are not at risk of hypercapnia. ${ }^{22}$ The rationale for this change is summarised in a separate publication. ${ }^{23}$ It seems unlikely that clinical outcomes will be affected much by this modest change in target saturation, and a very large study would be required to demonstrate differences in key outcomes such as mortality and length of stay related to this small adjustment. However, it is likely that less oxygen will be used in hospitals which adopt the TSANZ guidance; so, there may be a modest cost saving, and some patients may be mobilised and discharged more quickly due to earlier 'release' from oxygen therapy and associated tubing.

National BTS emergency oxygen audits since the release of the 2008 guideline have shown painfully slow progress in the change of practice relating to emergency oxygen administration. ${ }^{24}$ About $14 \%$ of UK hospital patients are using supplemental oxygen on any given day, but the proportion with a valid prescription for oxygen has risen only moderately from $32 \%$ in 2008 to $57 \%$ in 2015 , despite $85 \%$ of audited hospitals having an oxygen-prescribing policy. Of 4476 audited patients with a prescription for oxygen which included a target range, $69 \%$ of patients were within that range at the time of their most recent oxygen saturation measurement, 9\% were below the target range and $22 \%$ were above their target range.

Following publication of the new guideline, the key challenge is the implementation of principles that are now universally agreed but not always followed in the rough-and-tumble of clinical practice. The BTS, working together with key stakeholder organisations, will aim to build on the foundation laid since 2008 to ensure that the important guideline recommendations are fully implemented in day-to-day clinical practice. It is hoped that the guidelines will also continue to be regarded as the current best practice guide against which all new interventions will be tested in future randomised clinical trials.
Competing interests None declared.

Provenance and peer review Not commissioned; internally peer reviewed.

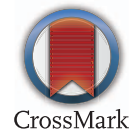

To cite O'Driscoll BR. Thorax 2017;72:498-499.

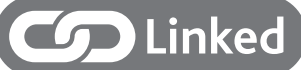

http://dx.doi.org/10.1136/thoraxjnl-2016-209729

http://dx.doi.org/10.1136/bmjresp-2016-000170

Thorax 2017;72:498-499.

doi:10.1136/thoraxjnl-2017-209951

\section{REFERENCES}

1 O'Driscoll BR, Howard LS, et al. British Thoracic Society. BTS guideline for emergency oxygen use in adult patients. Thorax 2008;63(Suppl VI): vi1-68.

2 Thorax reference for 2016 Guideline (in this issue of Thorax).

3 O'Driscoll BR, Howard LS, Earis J, et al. British Thoracic Society Guideline for oxygen use in adults in healthcare and emergency settings. BMJ Open Resp Res 2017. doi:10.1136/bmjresp-2016-000170.

4 AGREE II Instrument. Secondary AGREE ॥ Instrument. http://www.agreetrust.org/agree-ii/

5 Hardinge $M$, Annandale J, Bourne $S$, et al. British Thoracic Society guidelines for home oxygen use in adults. Thorax 2015;70(Suppl 1):i1-43.

6 Austin MA, Wills KE, Blizzard L et al. Effect of high flow oxygen on mortality in chronic obstructive pulmonary disease patients in prehospital setting: randomised controlled trial. BMJ 2010:341:c5462.

7 Roberts CM, Stone RA, Buckingham RJ, et al., National Chronic Obstructive Pulmonary Disease Resources and Outcomes Project implementation group. Acidosis, non-invasive ventilation and mortality in hospitalised COPD exacerbations. Thorax 2011;66:43-8.

8 Turner AM, Lim WS, Rodrigo C, et al. A care-bundles approach to improving standard of care in AECOPD admissions: results of a national project. Thorax 2015;70:992-4.

9 Wijesinghe $M$, Williams $M$, Perrin $K$, et al. The effect of supplemental oxygen on hypercapnia in subjects with obesity-associated hypoventilation: a randomized, crossover, clinical study. Chest 2011;139:1018-24.

10 Perrin K, Wijesinghe M, Healy B, et al. Randomised controlled trial of high concentration versus titrated oxygen therapy in severe exacerbations of asthma. Thorax 2011;66:937-41.

11 Wijesinghe M, Perrin K, Healy B, et al. Randomized controlled trial of high concentration oxygen in suspected community-acquired pneumonia. J $R$ Soc Med 2012;105:208-16.

12 Stub D, Smith K, Bernard S, et al. Air Versus Oxygen in ST-Segment-Elevation Myocardial Infarction. Circulation 2015;131:2143-50.

13 Nehme Z, Stub D, Bernard S, et al. Effect of supplemental oxygen exposure on myocardial injury in ST-elevation myocardial infarction. Heart 2016:102:444-51.

14 Wang $\mathrm{CH}$, Chang WT, Huang $\mathrm{CH}$, et al. The effect of hyperoxia on survival following adult cardiac arrest: a systematic review and meta-analysis of observational studies. Resuscitation 2014;85:1142-8.

15 Damiani E, Adrario E, Girardis M, et al. Arterial hyperoxia and mortality in critically ill patients: a systematic review and meta-analysis. Crit Care 2014;18:711.

16 Helmerhorst HJ, Roos-Blom MJ, van Westerloo DJ et al. Association Between Arterial Hyperoxia and Outcome in Subsets of Critical Illness: A Systematic Review, Meta-Analysis, and Meta-Regression of Cohort Studies. Crit Care Med 2015;43:1508-19.

17 Girardis M, Busani S, Damiani E, et al. Effect of conservative vs conventional oxygen therapy on mortality among patients in an Intensive Care Unit: The Oxygen-ICU Randomized Clinical Trial. JAMA 2016:316:1583-9.

18 Suzuki S, Eastwood GM, Glassford NJ, et al. Conservative oxygen therapy in mechanically ventilated patients: a pilot before-and-after trial. Crit Care Med 2014;42:1414-22.

19 Eastwood GM, Tanaka A, Espinoza ED, et al. Conservative oxygen therapy in mechanically ventilated patients following cardiac arrest: a retrospective nested cohort study. Resuscitation 2016;101:108-14.

20 Panwar R, Young P, Capellier G. Conservative oxygen therapy in mechanically ventilated patients. Crit Care Med 2014;42:e630-1

21 Helmerhorst HJ, Schultz MJ, van der Voort $\mathrm{PH}_{\text {, }}$ et al. Effectiveness and clinical outcomes of a two-step implementation of conservative oxygenation targets in critically ill patients: a before and after trial. Crit Care Med 2016:44:554-63.

22 Beasley R, Chien J, Douglas J, et al. Target oxygen saturation range: $92-96 \%$ versus $94-98$. Respirology 2017;22:200-2.

23 Beasley R, Chien J, Douglas J, et al. Thoracic Society of Australia and New Zealand oxygen guidelines for acute oxygen use in adults: 'Swimming between the flags'. Respirology 2015;20:1182-91

24 British Thoracic Society. Emergency Oxygen Audit Report. 2015. https://www.brit-thoracic.org.uk/ document-library/audit-and-quality-improvement/ audit-reports/bts-emergency-oxygen-audit-report-2015/ 